Article

\title{
Sustainable Agritourism in Thailand: Modeling Business Performance and Environmental Sustainability under Uncertainty
}

\author{
Ming-Lang Tseng ${ }^{1,2}, * \mathbb{D}$, Chia-Hao Chang ${ }^{3}$, Kuo-Jui $\mathrm{Wu}^{4}{ }^{4}$, Chun-Wei Remen Lin ${ }^{1}$, \\ Bhuripan Kalnaovkul ${ }^{3}$ and Raymond R. Tan ${ }^{5}$ \\ 1 Institute of Innovation \& Circular Economy, Asia University, Taichung 41345, Taiwan \\ 2 Department of Medical Research, China Medial University Hospital, China Medial University Taichung, \\ Taichung 404, Taiwan \\ 3 Department of Business Administration, Asia University, Taichung 41345, Taiwan \\ 4 School of Business, Dalian University of Technology, Panjin 124221, China \\ 5 Chemical Engineering Department, De La Salle University, Manila 24001, Philippines \\ * Correspondence: tsengminglang@asia.edu.tw
}

Received: 8 June 2019; Accepted: 26 July 2019; Published: 29 July 2019

check for updates

\begin{abstract}
This study aims to identify the causal attributes of sustainable agritourism in Thailand. Agritourism is a systematic approach based on farm diversification for tourism purposes. Agritourism is usually assessed with qualitative information. However, the assessment of agritourism attributes involves considering the interrelationships among the attributes. Prior studies on sustainable agritourism do not identify and address interrelated attributes using qualitative information. This study applies the Delphi method to identify a set of valid attributes. Moreover, this study applies triangular fuzzy numbers to transform the qualitative information into comparable values and uses a decision-making trial and evaluation laboratory to identify the interrelationships among the attributes in the causal model. The results show that sustainable business performance and rural economic conditions are the key drivers of environmental sustainability. This result suggests that the attributes that may potentially stimulate sustainable agritourism are the development and implementation of an agritourism-specific plan, the development of a local business value chain, and government-led tourism promotion.
\end{abstract}

Keywords: sustainable agritourism; Delphi method; triangular fuzzy numbers; decision-making trial and evaluation laboratory; triple bottom line

\section{Introduction}

Sustainable agriculture is the practice of using an integrated farming system of plants and animals that employs ecological and economic principles and considers the relationship between stakeholders and the environment. Sustainable agriculture tourism (agritourism) was introduced to farmers' stakeholders in Thailand to rehabilitate natural resources and the environment. The goal of sustainable agritourism is not only to optimize the economic benefits but also to achieve maximum benefits for the stakeholders, improve quality of life, and promote environmental conservation. Agritourism in Thailand is promoted to help farmers become self-sufficient and is practiced by all professions throughout the country. Agritourism activities are based on ecological and environmental preservation to ensure that the health of ecosystems, the human population and the natural environment can be sustained. Agritourism includes diverse and integrated activities aiming to improve the environment and agricultural production, combines agriculture and forestation and focuses on cultivating cash crops and improving soil quality and biodiversity, increasing the variety and quantity of agricultural products. 
Hence, agritourism is a subset of rural tourism that uses a diverse array of farms as tourist destinations [1]. This is an economic activity with potential social, economic, and environmental or triple bottom line (TBL) impacts that are highly dependent on the local characteristics of a region [2-5]. Agritourism has the potential to stimulate rural economies via its positive effects on farm income [6-9]. However, the extent of the financial benefits and economic impact is still contested due to conservative estimates [3,10,11]. Yang [12] presented the economic and sociocultural attributes of agritourism. Other studies on agritourism have reported noneconomic (i.e., environmental and sociocultural) benefits, such as an increase in sustainable agricultural operations, the enhancement of farmers' economic benefits, and the stimulation of rural economies through ripple effects [13-15]. There is a consensus in the literature that social, environmental and economic perspectives are important for sustainable development. However, strategic agritourism attributes needs to be identified to understand the consensus on sustainable agritourism [16]. Hence, the attributes of sustainable agritourism must be considered.

Interest in agritourism has increased in both studies and policy because it presents a path for farm diversification to generate supplementary income $[15,17,18]$. Farms used for agritourism are often privately owned and provide tourists with recreational opportunities based on traditional local activities $[19,20]$. Farms also provide lodging coupled with authentic indigenous cultural experiences $[8,21]$. Agritourism thus requires a rural locality with a pristine natural environment, which, in turn, requires committed investment and business models to ensure that the local ecosystem is preserved in an attractive state. Scholars have argued that agritourism can support rural development by generating business revenue and has secondary ripple effects such as increasing employment and increased environmental protection $[13,22-24]$. There is a need to study how agritourism should be properly performed to address future challenges.

Agritourism can contribute to sustainable development in rural areas by preserving the local culture while generating supplementary incomes $[13,25,26]$. For example, scholars have quantified its economic and sociocultural impact on farming communities [27]. In addition, scholars have explored the influence of socioeconomic attributes on the effectiveness of agritourism businesses [28]. Scholars observed that farms engaged in agritourism usually do not use systematic strategic planning [29]. There are a limited number of agritourism studies based on the sustainability perspective, particularly on farms diversifying their green operations to engage in sustainable agritourism [30,31]. A lack of long-term strategies and reliance on ad hoc management often leads to unsustainability [3-5,32]. Farmers are vulnerable to declining incomes and thus must adopt business strategies to mitigate such risks. To fill this gap in the literature and to support sustainable agritourism activities, a set of attributes needs to be identified.

Prior studies have applied descriptive methods to identify effective agritourism business models [8,13,33]. For instance, Yang [12] used a qualitative information approach to study agritourism focusing on economic and sociocultural attributes that increase environmental and cultural conservation. In addition, those attributes are described using linguistic preferences, which are inherently vague and difficult to process in the model. Prior studies also assumed that linear relationships exist among the identified aspects. Prior studies do not identify a set of valid attributes [3,13,27]. Complicated interrelationships exist among the attributes, and there are studies presenting the interrelationships that exist among the hierarchical structure; however, these studies merely present the interrelationships among the attributes [22,34]. These studies do not properly address the interrelationship and qualitative information. Hence, this study proposes using fuzzy set theory to address the qualitative information, and a decision-making trial and evaluation laboratory (DEMATEL) is used to handle the interrelationships among the attributes.

The objective of this study is to identify the attributes for sustainable agritourism using qualitative information. This study applies an expert's linguistic preferences to the qualitative information and identifies the interrelationships among the aspects. The contributions of this study are as follows. (1) A set of attributes are identified based on qualitative information; (2) this study identifies the 
interrelationships among the aspects using a causal model; and (3) the criteria for improving industrial performance are presented.

This rest of this study is organized as follows. Section 2 discusses the background of agritourism, the proposed method, and the proposed attributes. Section 3 describes the methodology in detail. Section 4 presents the industrial background and results specifically for Thailand. Section 5 discusses the theoretical and industrial implications. The last section provides the conclusions and suggestions for future studies.

\section{Literature Review}

This section reviews the extant literature to identify theoretical gaps, analytical methods and proposed attributes.

\subsection{Sustainable Agritourism}

Sustainability dimensions have been increasingly relevant to agritourism $[3,35,36]$. The growing agritourism literature remains inconclusive regarding sustainable and strategic performance, particularly from the tourism firms' perspective. Agritourism generates both economic and noneconomic (i.e., sociocultural and environmental) benefits $[13,14,29]$. For instance, scholars concluded that agritourism helps preserve and generate interest in the cultural practices of local communities [37]. Wu et al. [16] discussed the economic contributions of sustainable tourism using a multifaceted perspective and argued that income from tourism, an increase in tourism, and employment are the major impacts of agritourism. Agritourism also requires the involvement of government agencies to develop and implement conservation plans for managing sustainable rural areas [15,38]. Agritourism becomes unsustainable if done without proper planning. In agritourism, farms where agriculture is currently being practiced also provide activities for tourists. Prior studies have focused on the economic impacts on both farms and neighboring areas as they are the main beneficiaries [39].

In the literature, Shih et al. [5] presented broader debates, which create a significant problem because 'the farm' must be understood as an economic entity and in terms of its social and cultural significance. These scholars identified agribusiness characteristics that can be used to define a working farm and showed how sustainable agribusinesses can be improved. The TBL perspective is applied as a guiding framework for agritourism [2,32,40]. Kim et al. [15] pointed out that farmers are focused on economic benefits, attesting to the primary role of agritourism in boosting regional and rural economies by diversifying the income sources of farm businesses, a favorable effect on the farm income that is usually observed. In general, these authors note that agritourism farms have been found to be more successful in increasing their income. Farm diversification, which reduces farm dependence on conventional agricultural activities, has emerged for different reasons in different places. Farm diversification is defined as the reorganization of fundamental farm resources (i.e., land, labor, and capital) and the development of alternative on-farm activities that are not directly linked to agricultural production [41-43]. However, there is a lack of consensus in the literature on the typology of the modes of diversification.

The classification used in the majority of previous studies is mainly for illustrative purposes rather than being an attempt to define categories from the farmers' perspectives [44,45]. Understanding farm diversification from firms' perspectives will therefore overcome the limitations of existing classification schemes. For instance, scholars suggested that agritourism be included as a form of farm diversification, where firms' decisions are driven by goals such as increasing revenues, reducing risks, maximizing the use of resources, cross marketing farm products, and other forms of value-adding [13,34,46,47]. The most dominant of these goals are economic goals $[29,30,48]$. This study is helpful because it addresses a key issue underlying wider debates by recognizing agritourism as a physical activity rather than a financial activity, which is especially important in terms of incorporating the large numbers of agricultural farmers that may farm on a part-time basis and those that are supported by other streams of income. In other words, the agricultural and tourist activities take place on a farm. 
Previous studies have mostly applied qualitative information to study sustainable agritourism $[2,3,18,49]$. For instance, scholars discussed destination development from the perspective of sustainability and emphasized contributing to local resident's quality of life in tourism planning [35]. In addition, scholars attempted to understand the attributes of tourist satisfaction and revisited the use of qualitative attributes [9]. These studies used the Likert scale for a questionnaire-based survey designed to improve agritourism for purposes of community development [37]. In addition, changes in tourists' buying behaviors has economic impacts on agritourism. However, the existing literature fails to satisfactorily account for these qualitative attributes. Hence, the qualitative attributes need to be quantified using a proper framework for effective use in decision-making.

\subsection{Proposed Attributes}

Sustainable agritourism needs to be justified by the attributes. This study aims to develop a set of attributes based on the TBL perspective and to balance the TBL perspective [50]. Prior studies have increased our understanding of the attributes of agritourism $[4,5,18]$. However, the TBL must consider agritourism attributes. Hence, sustainable agritourism must include farm diversification activities, environmental quality at the farm location, and the uniqueness of the local rural culture in relation to the TBL perspective. The opportunity to contribute to sustainable agritourism has also been found to be an important attribute. Again, there has been no study on the activities of farmers that can lead to sustainable agritourism. In general, sustainable agritourism should be more focused on the opportunities that agritourism provides for harmonizing the TBL perspectives and creating activities for consumers. This study contributes to enhancing the success of agritourism and meeting a need in the market.

The economy of a rural society can become sustainable by ensuring that tourism is promoted and that it benefits the farmers and rural communities. The proposed attributes include increased income and profit, the employment of family members, and the generation of local employment opportunities [13]. Scholars identified various perspectives on the political, social, ecological, economic, technological, and cultural aspects of community tourism development [49]. Tseng et al. [3] confirmed that collaboration used to secure a competitive advantage by considering tourism stakeholders can generate social capital and thus help develop sustainable forms of tourism that improve financial performance levels. Environmental management issues such as water use, waste generation, energy consumption, and pollution should also be considered [39,51]. Diversification strategies and the attributes of success differ depending on the rural context $[13,29,37,47]$.

Sustainable agritourism seeks to minimize the impacts to the environment by reducing environmental impacts, reusing resources, recycling all useful materials and equipment, prioritizing the quality of services and increasing the number of visitors. Farmers seek social and economic development that also conserve the local culture and activities. For a rural society to have a sustainable economy, it is important to integrate the TBL perspective, which is essential for poverty eradication. Hence, farm household members working for agritourism contribute to the local economy through ripple effects such as increased spending on goods and services [33,52]. Increasing the business activity in the locality is closely linked to the diversification ability of farms. Hence, five aspects are included in this study 1. Sustainable business performance (A1); 2. Sustainable economy of rural society (A2); 3. Sociocultural sustainability (A3); 4. Environmental sustainability (A4); and Diversification ability of farms (A5).

Sustainable business performance (A1) in rural areas indicates that there has been an increase in the number of domestic tourists who consume products or services. Agritourism includes a series of activities, such as working as a housekeeper, helping with the front-of-house work in hotels, and visiting restaurants and attractions. Consumers flow into the region and spend money on byproducts or become involved in agricultural activities. These agritourism activities increase the average income of farmers through farm product sales to tourists. Agritourism activities increase total farm profit $[3,13,50]$. 
However, these sustainable agritourism activities show that there is a relationship between the number of tourists and the amount of the budget spent on the activities.

The sustainable economy of a rural society (A2) is vital to the TBL perspective, which is essential for poverty eradication because global poverty is overwhelmingly rural. The TBL perspective is therefore critical, and there is great value to be gained by coordinating rural development that contributes to sustainable livelihoods through the efforts of farm household members working for agritourism and in local employment. Strategies for rural development take into consideration local employees' incomes and livelihoods and the increased number of small businesses in rural areas, which generate strong linkages to TBL perspectives to enhance the participation of rural people and communities $[13,37,39]$.

In practice, sociocultural sustainability (A3) is the planning and evaluation of tourism development and often focuses only upon rapid economic and environmental impacts; it is significant because it considers both the society and the culture. There are many possibilities and challenges of rural community-based tourism development, in terms of sociocultural sustainability, in host communities. For instance, farm family members choose to stay in the farm household and integrate agriculture and the local culture into tourism. Prior studies have argued that the sociocultural aspects of agritourism have received little attention in the sustainable agritourism debate, and there is a fundamental need to improve the social and cultural circumstances $[13,39,49]$. Nevertheless, the continuation of traditional knowledge of farm practices can be used to promote traditional culture. Tourists participate in social and cultural activities in local areas to understand the culture in the local region.

Environmental sustainability (A4) is a responsible and sustainable form of agritourism. However, there have also been counterarguments. Community control and participation are a part of environmental sustainability. Community agritourism is small-scale tourism that brings only minimal economic growth and may not reduce poverty in rural areas $[13,39,49]$. For instance, environmentally-friendly farms and agribusiness practices focus on environmental sustainability to generate ecotourism, and environmentally conscious communities focus on sustainable economic growth; the conservation of water, electricity, and energy; and the protection of local fauna and flora. However, environmental sustainability ensures that our lives are comfortable while we meet our needs for water and food and engage in waste management practices [16]. Sustainable agritourism includes leisure activities and entertainment that do not cause damage to the environment or deplete resources that we cannot renew.

The diversification ability of farms (A5) can lead to an increase in the satisfaction of tourists and the number of revisiting tourists. Therefore, agritourism-specific plans and their implementation must consider the needs of tourists and simplify the range of agricultural outputs. The development of a local business value chain can lead to a better understanding of what motivates farmers to diversify their agricultural outputs and can contribute valuable insights. Clarifying the motives leading to involvement in government-led tourism promotion and the diversification of farmers is important because this ability to diversify has environmental and economic benefits for farm operations [13,29,47]. Table 1 presents the proposed attributes used to measure sustainable agritourism.

Table 1. Proposed attributes.

\begin{tabular}{|c|c|c|c|}
\hline Aspects & & Criteria & References \\
\hline \multirow{4}{*}{$\begin{array}{l}\text { Sustainable business } \\
\text { performance (A1) }\end{array}$} & $\mathrm{C} 1$ & Increased number of domestic tourists & \multirow{4}{*}[3,13,50]{} \\
\hline & $\mathrm{C} 2$ & Improved average income from tourists & \\
\hline & $\mathrm{C} 3$ & Improved average income from farm product sales & \\
\hline & $\mathrm{C} 4$ & Increased total farm profit including agritourism & \\
\hline \multirow{4}{*}{$\begin{array}{l}\text { Sustainable economy } \\
\text { of rural society (A2) }\end{array}$} & $\mathrm{C} 5$ & Farm household members working for agritourism & \multirow{4}{*}[13,37,39]{} \\
\hline & C6 & Contribution to local employment & \\
\hline & $\mathrm{C} 7$ & Contribution to local employees' incomes and & \\
\hline & $\mathrm{C} 8$ & Increased number of small businesses in the local area & \\
\hline
\end{tabular}


Table 1. Cont.

\begin{tabular}{|c|c|c|c|}
\hline Aspects & & Criteria & References \\
\hline \multirow{4}{*}{$\begin{array}{c}\text { Sociocultural } \\
\text { sustainability (A3) }\end{array}$} & C9 & $\begin{array}{l}\text { Farm family member choosing to stay in the farm } \\
\text { household }\end{array}$ & \multirow{4}{*}[13,39,49]{} \\
\hline & $\mathrm{C} 10$ & $\begin{array}{l}\text { Application of agriculture and the local culture to } \\
\text { tourism }\end{array}$ & \\
\hline & $\mathrm{C} 11$ & Continuation of traditional knowledge of farm practices & \\
\hline & $\mathrm{C} 12$ & Participation in social and cultural activities in local area & \\
\hline \multirow{4}{*}{$\begin{array}{c}\text { Environmental } \\
\text { sustainability (A4) }\end{array}$} & $\mathrm{C} 13$ & $\begin{array}{l}\text { Environmentally-friendly farm and agribusiness } \\
\text { practices }\end{array}$ & \multirow{4}{*}[13,39,49]{} \\
\hline & C14 & Protection of (indigenous) local fauna and flora & \\
\hline & $\mathrm{C} 15$ & Conservation of water, electricity, and energy & \\
\hline & $\mathrm{C} 16$ & Waste management practices & \\
\hline \multirow{5}{*}{$\begin{array}{l}\text { Diversification ability } \\
\text { of farms (A5) }\end{array}$} & $\mathrm{C} 17$ & Increased satisfaction of tourists & \multirow{5}{*}[13,29,47]{} \\
\hline & $\mathrm{C} 18$ & Increased number of revisiting tourists & \\
\hline & C19 & Agritourism-specific plan and implementation & \\
\hline & $\mathrm{C} 20$ & Development of local business value chain & \\
\hline & $\mathrm{C} 21$ & Involvement in government-led tourism promotion & \\
\hline
\end{tabular}

\section{Methods}

This section discusses the industrial background and proposed fuzzy DEMATEL method.

\subsection{Industrial Background}

The tourism industry relies on tourists' desire for relaxation and immersion in an authentic local experience. Thailand, which is already a popular destination for foreign tourists, stands to benefit from the enhancement of the economy's agricultural sector through the adoption of agritourism. In Thailand, there are 400 agricultural firms engaged in a variety of activities are engaged in agritourism. The Thailand government promotes agritourism as an alternative rural development mechanism and regulates it. Agritourism is a subsector of the tourism industry. Agritourism supports farm activities targeting tourists, including farm demonstrations, farm visits, farm training, etc., as well as on-site value-adding and sales of farm products. Agritourism occurs on a working farm or agricultural plant and is conducted for the visitors' enjoyment and to generate supplemental income for farmers. Agritourism and nature-tourism farms might include a diverse array of activities such as outdoor recreation, farming experiences, cultural entertainment, hospitality services and on-farm direct sales.

Agritourism is a subset of rural tourism that includes resorts, off-site farmers' markets and other leisure and hospitality businesses that attract visitors to the countryside. The attributes of tourism, as a market, are important. Attributes are often differentiated and recognized by tourism marketers as being important for decision makers of sustainable agritourism development. This study considers value-added agritourism activities and their attributes. Agritourism is still in the new development stage, and there are many attributes to be developed. Hence, this study identifies the attributes considering expert validity and context validity. This study provides an assessment based on the input of 21 experts from the academic, tourism and government sectors. These experts are experienced in agritourism activities in Thailand, see Appendix A. The proposed attributes are selected based on the literature review and actual agritourism activities that occur in Thailand. Rounds of questionnaires were sent out to the experts, and the anonymous responses were aggregated and shared with the research group.

\subsection{Delphi Method}

For this study, a group of experts on agritourism was selected. All participants were confirmed, and all the members of the group received a questionnaire with instructions to comment on the selected attributes based on their personal opinions. The questionnaires were returned, and the comments were grouped. This study considers this set of attributes to further assess agritourism activities in Thailand. 


\subsection{Fuzzy DEMATEL}

Triangular fuzzy number (TFN) provides an effective means of quantifying human linguistic preferences into computable form $[3,53]$. TFNs can be defined in terms of membership functions $\widetilde{\mathcal{W}}_{i j}^{k}=\left(\widetilde{l}_{L i j^{\prime}}^{k} \widetilde{m}_{M i j^{\prime}}^{k} \widetilde{u}_{U i j}^{k}\right)$ and processed in terms of well-established rules for fuzzy arithmetic (See, Table 2) [54]. These computations can be embedded into the DEMATEL technique, which provides a way to elucidate the complex interrelationships that exist among attributes in a given problem [55]. DEMATEL can also provide a visual representation of these interrelationships to aid in decision-making. The use of TFNs in DEMATEL results in a fuzzy DEMATEL analytical process.

Table 2. Fuzzy linguistic preferences.

\begin{tabular}{lccc}
\hline Linguistic Preferences & $\tilde{t}_{\mathbf{L i j}}^{k}$ & $\tilde{t}_{\mathbf{M} i j}^{k}$ & $\tilde{t}_{\mathbf{U} i j}^{k}$ \\
\hline no influence & 0 & 0.1 & 0.3 \\
very low influence & 0.1 & 0.3 & 0.5 \\
low influence & 0.3 & 0.5 & 0.7 \\
high influence & 0.5 & 0.7 & 0.9 \\
very high influence & 0.7 & 0.9 & 1.0 \\
\hline
\end{tabular}

Assume that a proposed measure is composed of a set of attributes $\check{T}=\left\{t^{\prime} 1, t^{\prime} 2, t^{\prime} 3, \cdots, t^{\prime} n\right\}$. The attributes are confirmed in terms of content and expert validity. The content validity ratio is measured by the yield values, which range from +1 to -1 ; positive values indicate that at least half of the domain of expert raters rated the attribute as essential. The content validity ratio is thus an indicator of overall test content validity. A particular value for pairwise interdependency is decided for modeling this mathematical relation. The analytical procedures are presented below.

\section{Step 1: Obtaining and aggregating the crisp values}

Calculating the fuzzy direct relation matrix between attributes requires the comparison scale to be designed into five linguistic preferences: no influence, very low influence, low influence, high influence and very high influence. Suppose there are $k$ members in the decision group that make the assessment $\bar{t}_{i j}^{k}$, which represents the fuzzy weight of the $i^{t h}$ attribute affecting the $j^{\text {th }}$ attribute assessed by $k^{\text {th }}$ evaluators.

Normalizing the corresponding fuzzy numbers:

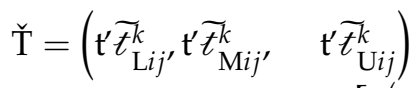

$$
\begin{aligned}
& =\left[\frac{\left(t_{\mathrm{L} i j}^{k}-\min t_{\mathrm{L} i j}^{k}\right)}{\max _{\mathrm{U} i j}^{k}-\min t_{\mathrm{L} i j}^{k}}, \frac{\left(t_{\mathrm{m} i j}^{k}-\min t_{\mathrm{m} i j}^{k}\right)}{\max t_{\mathrm{U} i j}^{k}-\min t_{\mathrm{L} i j}^{k}}, \frac{\left(t_{\mathrm{U} i j}^{k}-\min t_{\mathrm{U} i j}^{k}\right)}{\max t_{\mathrm{U} i j}^{k}-\min t_{\mathrm{L} i j}^{k}}\right]
\end{aligned}
$$

By computing the left $(\ell)$ and right $(\nabla)$ normalized value:

$$
\left(\ell_{i j}^{x}, \nabla_{i j}^{x}\right)=\left[\frac{\mathfrak{t}^{\prime} t_{\mathrm{M} i j}^{k}}{\left(1+\mathfrak{t}^{\prime} t_{\mathrm{M} i j}^{k}-\mathfrak{t}^{\prime} t_{\mathrm{L} i j}^{k}\right)}, \frac{\mathfrak{t}^{\prime} t_{\mathrm{U} i j}^{k}}{\left(1+\mathfrak{t}^{\prime} t_{\mathrm{U} i j}^{k}-\mathfrak{t}^{\prime} t_{\mathrm{M} i j}^{k}\right)}\right]
$$

The total normalized crisp value $(c)$ :

$$
c_{i j}^{k}=\left[\ell_{i j}^{k}\left(1-\ell_{i j}^{k}\right)+\left(\nabla_{i j}^{k}\right)^{2}\right] /\left(1-\ell_{i j}^{k}+\nabla_{i j}^{k}\right)
$$

We adopted the synthetic value notation to aggregate the subjective judgement for $k$ respondents.

$$
\tilde{\hat{\mathrm{W}}}_{i j}^{k}=\left(c_{i j}^{1}+c_{i j}^{2}+c_{i j}^{3}+\cdots+c_{i j}^{\mathrm{k}}\right) / k
$$


Step 2: Arranging the pairwise comparisons into the initial direct relation matrix

The initial direct relation matrix $(\mathcal{M})$ is a $n \times n$ matrix obtained by pairwise comparisons. $\widetilde{w}_{i j}^{k}$ denotes the degree to which attribute $i$ affects attribute $j$. Moreover, the initial direct relation matrix is $\mathcal{M}=\left[\tilde{\hat{\mathrm{W}}}_{i j}^{k}\right]_{n \times n}$.

Step 3: Generating the normalized direct relation matrix

The normalized direct relation matrix $(\mathcal{N})$ is generated as follows:

$$
\varphi=\frac{\mathcal{N}=\varphi \otimes \mathcal{M}}{\max _{1 \leq i \leq k} \sum_{j=1}^{k} \widetilde{\widetilde{W}}_{i j}^{k}}
$$

Step 4: Attaining the total interrelationship matrix

The normalized direct relation matrix assists in attaining the total interrelationship matrix $(t)$.

$$
t=\mathcal{N}(I-\mathcal{N})^{-1}
$$

where $t$ is $\left[t_{i j}\right]_{n \times n} i, j=1,2, \cdots n$

Step 5: Mapping the causal interrelationship diagram

Employing the following equations, the driving power $(D)$ and dependence power $(R)$ can be obtained based on the total relation matrix by summing the rows and columns.

$$
\begin{aligned}
& D=\left[\sum_{i=1}^{n} t_{i j}\right]_{n \times n}=\left[t_{i}\right]_{n \times 1} \\
& R=\left[\sum_{j-1}^{n} t_{i j}\right]_{n \times n}=\left[t_{j}\right]_{1 \times n}
\end{aligned}
$$

The causal interrelationship diagram can be drawn through the attributes using $(D+R, D-R)$. $(D+R)$ is used to express the horizontal axis, which is called "Prominence" for presenting the importance of attributes. $(D-R)$ is the vertical axis and represents the "Relation" for displaying the cause and effect interrelationship among attributes. If an attribute's $(D-R)$ has a positive value, the attribute belongs to the causal group; conversely, when the attribute possesses negative values of $(D-R)$, it belongs to the effect group.

\section{Results}

Table 3 presents the aspects of TFN according to respondent 1 . Defuzzification is applied in Equations (1)-(3). This study integrated the responses from 21 expert respondents from the Thailand agritourism industry to compose the initial direct relation matrix using Equation (4).

The initial direct relation matrix $(\mathcal{M})$ aggregates the expert's responses. The initial direct relation matrix $(\mathcal{M})$ generates the normalized direct relation matrix $(\mathcal{N})$ using Equation (5). Equation (6) is used to develop the total interrelationship matrix $(t)$. The total interrelationship matrix $(t)$ is used to judge the interrelationship cut-off value for the interrelationship levels (strong, medium, weak and no interrelationship). 
Table 3. Respondent 1: the aspects' triangular fuzzy numbers and defuzzified numbers are transformed into crisp values.

\begin{tabular}{|c|c|c|c|c|c|c|c|c|c|c|c|c|c|c|c|c|c|c|c|c|}
\hline & \multicolumn{3}{|c|}{ A1 } & \multicolumn{4}{|c|}{ A2 } & \multicolumn{4}{|c|}{ A3 } & \multicolumn{4}{|c|}{ A4 } & \multicolumn{5}{|c|}{ A5 } \\
\hline A1 & 1.000 & 1.000 & $1.000]$ & [ & 0.500 & 0.700 & $0.900]$ & {[} & 0.100 & 0.300 & $0.500]$ & [ & 0.300 & 0.500 & $0.700]$ & [ & 0.500 & 0.700 & 0.900 & ] \\
\hline A2 & 0.300 & 0.500 & $0.700]$ & [ & 1.000 & 1.000 & $1.000]$ & {[} & 0.100 & 0.300 & $0.500]$ & {[} & 0.300 & 0.500 & $0.700]$ & {[} & 0.100 & 0.300 & 0.500 & ] \\
\hline A3 & 0.300 & 0.500 & $0.700]$ & [ & 0.300 & 0.500 & $0.700]$ & {[} & 1.000 & 1.000 & $1.000]$ & {[} & 0.300 & 0.500 & $0.700]$ & {[} & 0.300 & 0.500 & 0.700 & ] \\
\hline A4 & 0.100 & 0.300 & $0.500]$ & [ & 0.300 & 0.500 & $0.700]$ & {[} & 0.500 & 0.700 & $0.900]$ & [ & 1.000 & 1.000 & $1.000]$ & [ & 0.300 & 0.500 & 0.700 & ] \\
\hline \multirow[t]{2}{*}{ A5 } & 0.500 & 0.700 & $0.900]$ & [ & 0.500 & 0.700 & $0.900]$ & [ & 0.300 & 0.500 & $0.700]$ & [ & 0.300 & 0.500 & $0.700]$ & [ & 1.000 & 1.000 & 1.000 & ] \\
\hline & $\widetilde{t}_{\mathrm{L} i j}^{k}$ & $\bar{t}_{\mathrm{M} i j}^{k}$ & $\widetilde{t}_{\mathrm{U} i j}^{k}$ & & $\widetilde{t}_{\mathrm{L} i j}^{k}$ & $\bar{t}_{\mathrm{M} i j}^{k}$ & $\widetilde{t}_{\mathrm{U} i j}^{k}$ & & $\widetilde{t}_{\mathrm{L} i j}^{k}$ & $\bar{t}_{\mathrm{M} i j}^{k}$ & $\widetilde{t}_{\mathrm{U} i j}^{k}$ & & $\bar{t}_{\mathrm{Lij}}^{k}$ & $\bar{t}_{\mathrm{M} i j}^{k}$ & $\widetilde{t}_{\mathrm{U} i j}^{k}$ & & $\widetilde{t}_{\mathrm{L} i j}^{k}$ & $\widetilde{t}_{\mathrm{M} i j}^{k}$ & $\widetilde{t}_{\mathrm{U} i j}^{k}$ & \\
\hline A1 & 1.000 & 0.778 & $0.556]$ & [ & 0.286 & 0.286 & $0.286]$ & {[} & 0.000 & 0.000 & $0.000]$ & [ & 0.000 & 0.000 & $0.000]$ & {[} & 0.444 & 0.444 & 0.444 & ] \\
\hline A2 & 0.222 & 0.222 & $0.222]$ & [ & 1.000 & 0.714 & $0.429]$ & {[} & 0.000 & 0.000 & $0.000]$ & {[} & 0.000 & 0.000 & $0.000]$ & [ & 0.000 & 0.000 & 0.000 & ] \\
\hline A3 & 0.222 & 0.222 & $0.222]$ & [ & 0.000 & 0.000 & $0.000]$ & [ & 1.000 & 0.778 & $0.556]$ & [ & 0.000 & 0.000 & $0.000]$ & [ & 0.222 & 0.222 & 0.222 & ] \\
\hline A4 & 0.000 & 0.000 & $0.000]$ & [ & 0.000 & 0.000 & $0.000]$ & [ & 0.444 & 0.444 & $0.444]$ & [ & 1.000 & 0.714 & $0.429]$ & [ & 0.222 & 0.222 & 0.222 & ] \\
\hline \multirow[t]{2}{*}{ A5 } & 0.444 & 0.444 & $0.444]$ & [ & 0.286 & 0.286 & $0.286]$ & [ & 0.222 & 0.222 & $0.222]$ & [ & 0.000 & 0.000 & $0.000]$ & [ & 1.000 & 0.778 & 0.556 & ] \\
\hline & $\ell_{i j}^{x}$ & $\nabla_{i j}^{x}$ & & & $\ell_{i j}^{x}$ & $\nabla_{i j}^{x}$ & & & $\ell_{i j}^{x}$ & $\nabla_{i j}^{x}$ & & & $\ell_{i j}^{x}$ & $\nabla_{i j}^{x}$ & & & $\ell_{i j}^{x}$ & $\nabla_{i j}^{x}$ & & \\
\hline A1 & 1.000 & 0.714 & & & 0.286 & 0.286 & & & 0.000 & 0.000 & & & 0.000 & 0.000 & & & 0.444 & 0.444 & & \\
\hline A2 & 0.222 & 0.222 & & & 1.000 & 0.600 & & & 0.000 & 0.000 & & & 0.000 & 0.000 & & & 0.000 & 0.000 & & \\
\hline A3 & 0.222 & 0.222 & & & 0.000 & 0.000 & & & 0.000 & 0.714 & & & 0.000 & 0.000 & & & 0.222 & 0.222 & & \\
\hline A4 & 0.000 & 0.000 & & & 0.000 & 0.000 & & & 0.444 & 0.444 & & & 1.000 & 0.600 & & & 0.222 & 0.222 & & \\
\hline \multirow[t]{2}{*}{ A5 } & 0.444 & 0.444 & & & 0.286 & 0.286 & & & 0.222 & 0.222 & & & 0.000 & 0.000 & & & 1.000 & 0.714 & & \\
\hline & $c_{i j}^{k}$ & & & & $c_{i j}^{k}$ & & & & $c_{i j}^{k}$ & & & & $c_{i j}^{k}$ & & & & $c_{i j}^{k}$ & & & \\
\hline A1 & 0.743 & & & & 0.500 & & & & 0.100 & & & & 0.300 & & & & 0.500 & & & \\
\hline A2 & 0.300 & & & & 0.720 & & & & 0.100 & & & & 0.300 & & & & 0.100 & & & \\
\hline A3 & 0.300 & & & & 0.300 & & & & 0.368 & & & & 0.300 & & & & 0.300 & & & \\
\hline A4 & 0.100 & & & & 0.300 & & & & 0.500 & & & & 0.720 & & & & 0.300 & & & \\
\hline A5 & 0.500 & & & & 0.500 & & & & 0.300 & & & & 0.300 & & & & 0.743 & & & \\
\hline
\end{tabular}


Using Equations (7) and (8), we classify sustainable business performance (A1), sustainable economy of rural society (A2), sociocultural sustainability (A3) and diversification ability of farms (A5) as the cause aspects group, as shown in Table 4.

Table 5 presents the cause group (A1, A2, A3 and A5) and effect group (A4). The aspect's two-way effects occur for sustainable business performance (A1), sustainable economy of rural society (A2), and diversification ability of farms (A5). There are no interrelationships among A1 and A3.

Table 4. The importance and causal effect of each aspect.

\begin{tabular}{ccccc}
\hline & $\mathbf{D}$ & $\mathbf{R}$ & $\mathbf{D}+\mathbf{R}$ & $\mathbf{D}-\mathbf{R}$ \\
\hline A1 & 10.020 & 9.837 & 19.856 & 0.183 \\
A2 & 9.627 & 9.288 & 18.915 & 0.339 \\
A3 & 7.203 & 7.092 & 14.295 & 0.111 \\
A4 & 7.772 & 8.917 & 16.689 & $(1.144)$ \\
A5 & 9.185 & 8.674 & 17.859 & 0.511 \\
\hline \multicolumn{5}{c}{ D: driving power; R: dependence power. }
\end{tabular}

Table 5. Interrelationships among the aspects.

\begin{tabular}{cccccc}
\hline & A1 & A2 & A3 & A4 & A5 \\
\hline A1 & 2.3284 & 2.1254 & 0.0000 & 2.0350 & 1.9659 \\
A2 & 2.1718 & 2.1322 & 0.0000 & 1.9132 & 1.8651 \\
A3 & 0.0000 & 0.0000 & 0.0000 & 0.0000 & 0.0000 \\
A4 & 0.0000 & 0.0000 & 0.0000 & 0.0000 & 0.0000 \\
A5 & 2.0711 & 1.8921 & 0.0000 & 1.8206 & 1.9325 \\
\hline
\end{tabular}

Figure 1 presents the interrelationship among the aspects. The cause group includes sustainable business performance (A1), sustainable economy of rural society (A2), and diversification ability of farms (A5). Sociocultural sustainability (A3) is not interrelated with any other aspects. A medium effect exists among A1, A2 and A4.

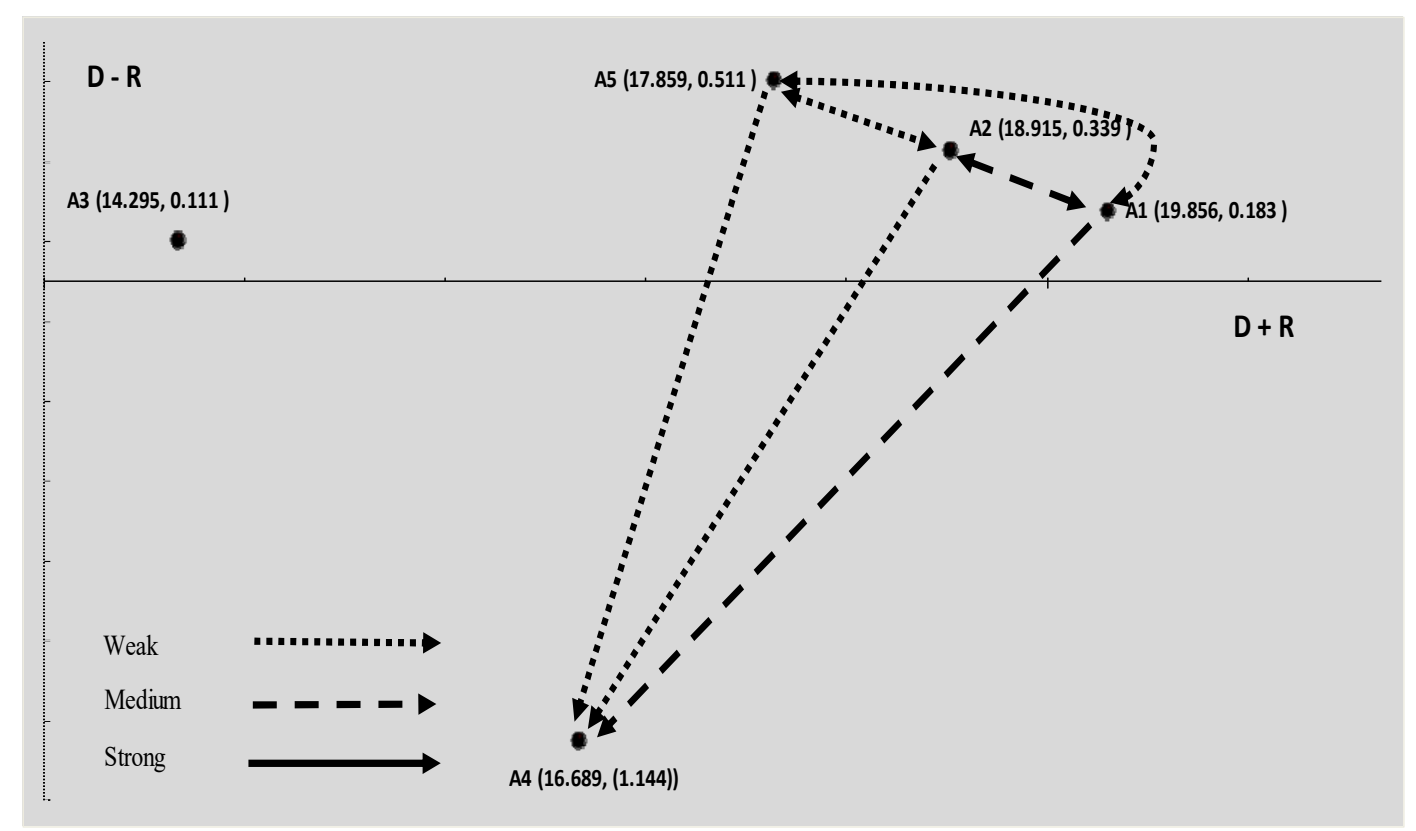

Figure 1. The impact diagram map of the relations among the sustainable agribusiness aspects. 
Again, the total interrelationship matrix $(t)$ is generated from Equation (6). Equations (7) and (8) are used to acquire $(D+R)$, which is used to express the horizontal axis, and $(D-R)$, which is the vertical axis, representing the "Relation". This matrix illustrates the cause and effect interrelationships among the attributes, showed in Table 6.

Table 6. The importance and causal effect of each criterion.

\begin{tabular}{ccccc}
\hline & $\mathbf{D}$ & $\mathbf{R}$ & $\mathbf{D}+\mathbf{R}$ & $\mathbf{D}-\mathbf{R}$ \\
\hline C1 & 8.4725 & 10.0364 & 18.5089 & $(1.5639)$ \\
C2 & 8.4326 & 9.8768 & 18.3094 & $(1.4442)$ \\
C3 & 7.6859 & 8.8865 & 16.5724 & $(1.2006)$ \\
C4 & 8.9606 & 9.4149 & 18.3755 & $(0.4544)$ \\
C5 & 8.7920 & 7.5768 & 16.3688 & 1.2152 \\
C6 & 8.1428 & 7.2608 & 15.4037 & 0.8820 \\
C7 & 8.4815 & 7.3845 & 15.8660 & 1.0970 \\
C8 & 8.7479 & 8.1096 & 16.8576 & 0.6383 \\
C9 & 8.3013 & 6.6391 & 14.9403 & 1.6622 \\
C10 & 8.8320 & 8.1638 & 16.9958 & 0.6682 \\
C11 & 8.5658 & 7.7155 & 16.2813 & 0.8503 \\
C12 & 9.2475 & 8.9392 & 18.1866 & 0.3083 \\
C13 & 9.0729 & 8.8570 & 17.9299 & 0.2160 \\
C14 & 7.1457 & 7.0073 & 14.1530 & 0.1384 \\
C15 & 7.8536 & 8.0452 & 15.8988 & $(0.1916)$ \\
C16 & 7.7426 & 8.0803 & 15.8228 & $(0.3377)$ \\
C17 & 8.1209 & 10.0015 & 18.1225 & $(1.8806)$ \\
C18 & 7.2399 & 8.8135 & 16.0534 & $(1.5737)$ \\
C19 & 9.3226 & 9.0416 & 18.3642 & 0.2810 \\
C20 & 9.2347 & 9.2105 & 18.4452 & 0.0243 \\
C21 & 9.5519 & 8.8864 & 18.4383 & 0.6655 \\
\hline
\end{tabular}

Figure 2 presents the cause and effect criteria groups. The top five important cause groups are the Development of local business value chain (C20), Involvement in government-led tourism promotion (C21), Agritourism-specific plan and implementation (C19), Participation of social and cultural activity in local areas (C12), and Environmentally-friendly farm and agribusiness practices (C13).

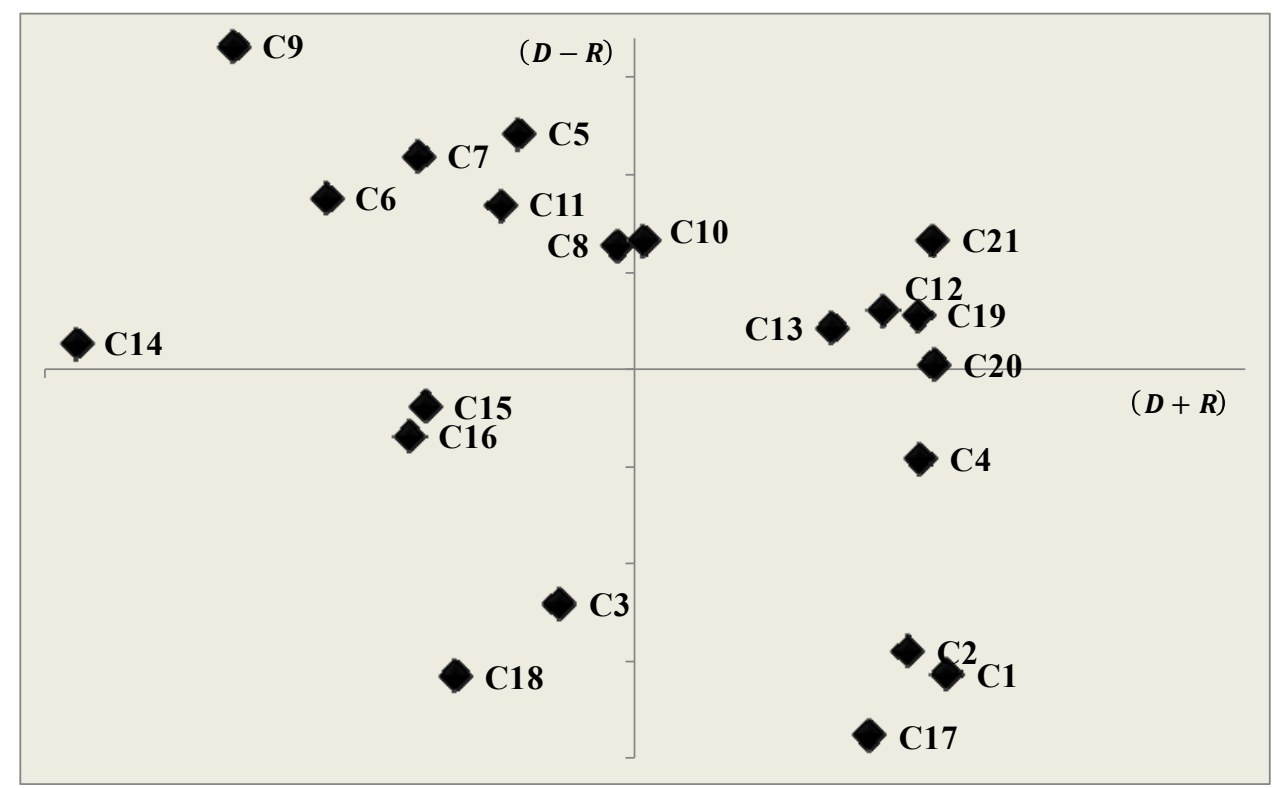

Figure 2. The impact diagram map of the relations among the sustainable agribusiness criteria. 


\section{Implications}

This section discusses the theoretical and industrial implications.

\subsection{Theoretical Implications}

Agritourism has often been implemented with enhanced farm revenue as the main objective $[9,13,48]$. Recently, there has been growing interest in potential agritourism contributions to rural economies as well as the conservation of sociocultural heritage and local ecosystems. Prior studies attempted to quantify the value of agritourism based on incremental farm income, but the assessment of secondary impacts of sustainable agritourism has been largely ignored. Hence, this study clarifies the relationships among the key attributes to improve our understanding of the drivers of sustainable agritourism. Furthermore, ref. [13] stated that agritourism has a great impact on the human capital of farms because household members can work on the farms. Sustainable business performance uses a balanced TBL perspective. The revenue gains based on increases in tourism levels need to be balanced with the need to conserve the local culture and environment. Sustainable practices thus ensure the long-term health and survival of businesses by considering the TBL perspective.

The results reveal a moderate mutual relationship with the sustainable economy of rural society (A2) and a weak mutual relationship with the diversification ability of farms (A5). These findings indicate that the complexity of sustainable agritourism is related to the interrelationship between the ability and adaptability of farms and the economy of the localities where the farms are situated [11,12]. In addition, sustainable business performance (A1) has a medium effect on environmental sustainability (A4). This is consistent with the notion that agritourism farms have positive environmental impacts, since diversified farms are usually engaged in environmentally-friendly farming practices [13]. This study also reveals the importance of agritourism in establishing long-term environmental sustainability. In summary, economic sustainability refers to firms' ability to provide for their current and future economic needs; social sustainability focuses on preserving the local culture while minimizing the permanent influence of the tourist influx; and environmental sustainability refers to the preservation of the environment so that agritourism remains attractive in the future.

This is consistent with the general understanding of agritourism as a means to supplement farm income. Nevertheless, the results clearly indicate that the sustainable economy of rural society (A2) and the diversification ability of farms (A5) are interrelated with sustainable agritourism. This study verifies that sustainable agritourism occurs only when there is a balance between the diversification ability of farms and the economic benefits of agritourism for both farms and rural society. Sociocultural sustainability (A3), however, does not have a relationship with the other attributes, has a minimal impact on sustainable agribusiness, and contributes the least to strategic agribusiness performance. Environmental sustainability (A4) is influenced by the long-term economic performance of both farms and rural society. The ability of farms to diversify impacts the environment. This finding indicates that agritourism is important for achieving environmental sustainability and suggests that agritourism should be designated one of the more sustainable rural development attributes because it has a less negative environmental impact than other forms of tourism.

\subsection{Industrial Implications}

The Thailand government coordinates development initiatives by instituting properly designed policies. Such policies provide the basis for individual farmers to select diversification pathways that do not overtax the local ecosystem or dilute the local rural culture. There is a significant risk of a sudden initial burst of development without such coordination; the farm owners act unilaterally to maximize their earnings from the tourist influx. This may lead to rapid growth in short-term earnings, but overexploitation leads to the erosion of both environmental quality and cultural authenticity. The community then incurs the long-term risk of losing the attributes that make for an attractive tourist destination and eventually, agritourism will underperform. In addition, proper regulation 
and coordination by the local authority can prevent poor economic performance. The cause aspects are sustainable business performance and the sustainable economy of rural society, which affect the environmental sustainability aspect. This study focuses on sustainable agritourism and shows that agritourism can be used as a diversification strategy to increase farms' economic benefits. The cause aspect is related to farms' revenue sources after they engage in agritourism to enhance their own sustainability. Operating sustainable agritourism is expected to increase sustainable business performance and enhance farm profitability.

The results identify the most influential attributes for sustainable agritourism providers and/or aspiring farmers who can use this information for promoting and marketing their products. Farmers may consider offering products or services to generate a profit, but this will have environmental and social impacts. Sustainable business performance should be aligned with TBL perspective planning. Thailand's sustainable agritourism aims to expose agritourists to agriproducts in a more meaningful way and offers various activities that increase consumers' involvement with agriproducts. Economic activities in localities are linked to agritourism. Benefits accrue to local entrepreneurs catering to tourist needs, which range from services (e.g., transportation) to tangible goods (e.g., food and local souvenirs). The provision of a local network that provides goods and services to tourists is essential to ensure successful agritourism and environmental sustainability. This integrated network serves to coordinate the activities of the local merchants to prevent either undersupply (which translates to opportunity costs) or oversupply (which can cause an undesired drop in the prices) of goods and services. Coordination within such a sustainable business network, in cooperation with the government agency in charge of agritourism, can also ensure the proper behavior of local businessmen and prevent practices that may detract from the long-term reputation of the tourist destination. An agritourism program should be designed to maximize the overall economic benefits to the sustainable economy of rural society and ensure that the farms and local merchants cater to tourist needs and that benefits from the program are equitably distributed among multiple stakeholders, as well as between the present and future needs of the rural community.

\section{Conclusions}

Agritourism stimulates rural economies by increasing farmers' incomes due to activity diversification and satisfies the visitors' needs. Rural regions with large volumes of visitors should consider the TBL perspective. Prior studies have used qualitative information to propose various attributes. Agritourism has the attribute of including various operational activities. This study concludes that activities in agricultural settings and the sociocultural environment are vital for sustainable business performance. This study identifies a set of sustainable agritourism attributes and constructs a causal model to improve our understanding of sustainable agritourism development. Hence, understanding the attributes can help decision makers in the government and private sector to develop efficient resource allocation. Qualitative information was used to identify the proposed aspects and criteria, and linguistic preferences exist. In addition, the attributes are interrelated. This study applies fuzzy DEMATEL to incorporate qualitative information and linguistic preferences into the analyses. The causal interrelationship model can be used to help decision makers understand the cause and effect relationships among the aspects.

The findings show that the interrelationships among the attributes show how sustainable business performance, sustainable rural economy development and farm diversification are interrelated. Sustainable business performance is a dominant aspect of sustainable agritourism performance, while sociocultural sustainability is interrelated with the aspects. Sustainable business performance incorporates the criteria and impacts the service processes, such as farm activities, inbound transportation, processing, waste collection, and outbound transportation. Visitors consider the design of the activities, the characteristics of the services and processes, consumption and disposal, and so on. These aspects are a part of the life cycle of the service and can be assessed. Nevertheless, sustainable business performance should focus on the TBL perspective for the whole service or operational 
process. The economic approach has forced firms to continuously improve their financial performance, while obeying market and government regulations. Meanwhile, visitors are demanding high-quality products and services that are consistent with their environmental cultural and social values.

The main contributions of this study are as follows. (1) This study identifies a set of attributes that can be used to assess sustainable agritourism; (2) by using qualitative information, this study develops a case and effect model based on the interrelationships among the attributes; (3) the proposed criteria are assessed for industrial practices, and we present the top five criteria in the cause group; and (4) this study shows that an agritourism-specific plan that takes into account the TBL should be integrated and implemented to ensure sustainability. The farmers have social and environmental responsibilities that require a continuing and progressive process of involvement and the development of the farms' competences. This study presents the social and environmental issues associated with the economic benefits and stakeholders, such as direct collaborators, partners and shareholders, suppliers, consumers, the market, competitors, and the community.

This study has some limitations. This study collected questionnaires from academic, government and farming experts. Perhaps a future study might compare the stakeholders' perceptions of sustainable agritourism. A future study might include some statistical data to assess the validity and reliability of the responses of the experts. This study considered five aspects and 21 criteria for assessing sustainable agritourism. A future study might increase the number of aspects and criteria. In addition, this study was based on the perceptions of a group of experts. The interviewees assessed qualitative information; perhaps quantitative data must be included in the study. These issues thus limit the generalizability of the findings. Finally, the mapping of the interrelationships among the aspects was based on the informants' input; thus, the objective and subjective perceptions might introduce bias. A sensitivity analysis could be included in a future study.

Author Contributions: M.-L.T. is review and revised the final paper. C.-H.C. is the resource of funding partially. K.-J.W. added the comments and improvement. C.-W.R.L. is final reviewed the draft paper. B.K. collected the data and drafts this manuscript. R.R.T. commented on the paper.

Funding: This research was funded by Ministry of Science and Technology, Taiwan grant number [108-2221-E-468-004-MY2].

Acknowledgments: We are particularly grateful to Bhuripan Kalnaovkul who selected the study respondents and collected the responses from Thailand.

Conflicts of Interest: The authors declare no conflicts of interest. 


\section{Appendix A. Questionnaire}

\begin{tabular}{|l|l|}
\hline \multicolumn{2}{|c|}{} \\
\hline \multirow{4}{*}{ Aspects } & Sustainable business performance (A1) \\
\cline { 2 - 3 } & Sustainable economy of a rural society (A2) \\
\cline { 2 - 3 } & Sociocultural sustainability (A3) \\
\cline { 2 - 3 } & Environmental sustainability (A4) \\
\cline { 2 - 3 } & Diversification ability of farms (A5) \\
\hline
\end{tabular}

Reminder of criteria assessment

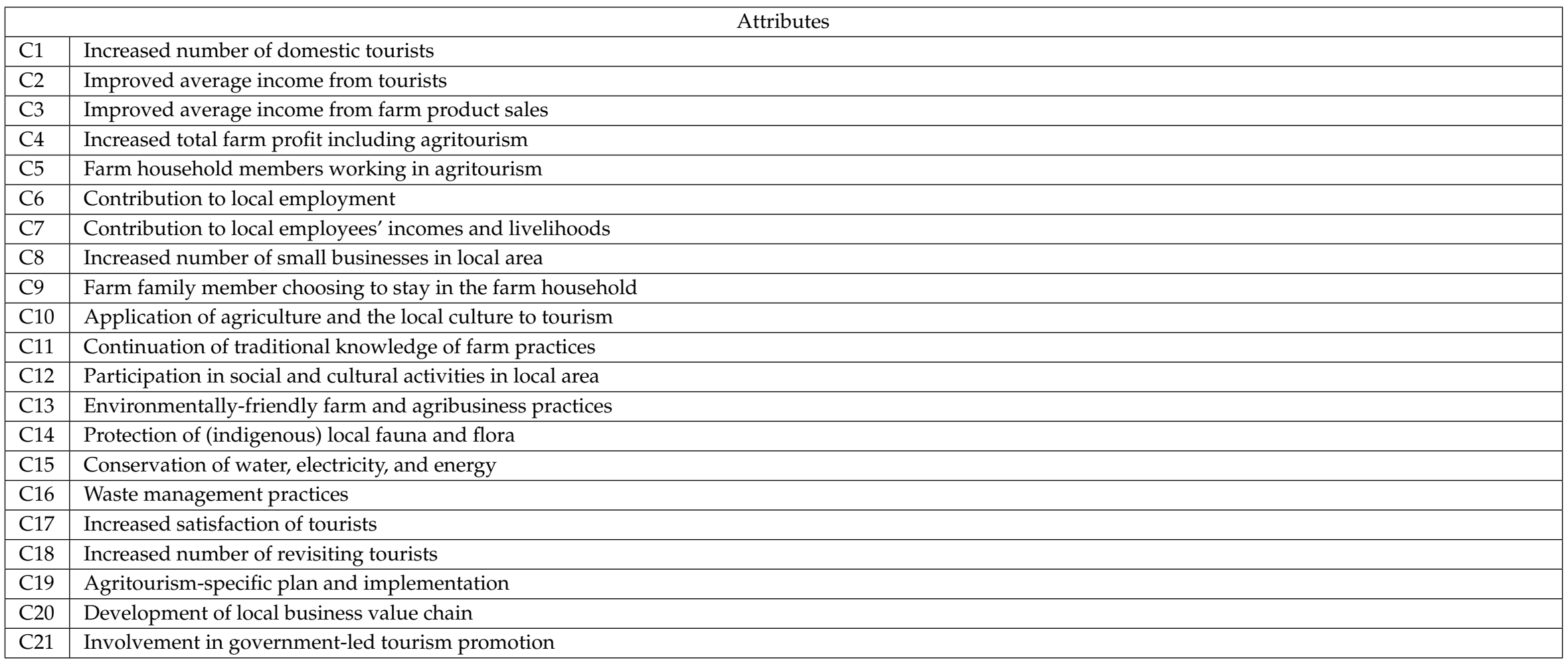


Directions: Please indicate your level of importance for each of these aspects and criteria statements regarding sustainable agritourism. Place a "VHI" "HI" "LI" "VLl" "NI" in the box of your answer.

\section{Importance degree}

no influence (NI)

very low influence (VLI)

low influence (LI)

high influence (HI)

very high influence (VHI)

For example: The assessment of criteria to criteria

\begin{tabular}{|c|c|c|c|c|c|c|c|c|c|c|c|c|c|c|c|c|c|c|c|c|c|c|c|}
\hline 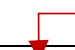 & $\mathrm{C} 1$ & $\mathrm{C} 2$ & $C^{3}$ & $\mathrm{C} 4$ & C5 & C6 & C7 & $\mathrm{C} 8$ & C9 & $\mathrm{C} 10$ & $\mathrm{C} 11$ & $\mathrm{C} 12$ & $\mathrm{C} 13$ & $\mathrm{C} 14$ & C15 & C16 & C17 & C18 & C19 & $\mathrm{C} 20$ & $\mathrm{C} 21$ & $\mathrm{C} 21$ & Important level \\
\hline C1 & $\mathrm{h}$ & & & & 4 & & & & & & & & & 4 & & & & & & & & & \\
\hline $\mathrm{C} 2$ & $\Longleftarrow$ & & & & + & & & & & & & & & $\vdots$ & & & & & & $\longrightarrow$ & & & vh \\
\hline C3 & & & $\mathrm{m}$ & & 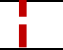 & & & & & & & & & 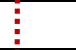 & & & & & & & & & \\
\hline C4 & 4 & - & שי & - & $-\forall h$ & & & & & & & & & 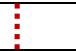 & & & & & & & & & \\
\hline $\mathrm{C} 5$ & & & & & & & & & & & & & & 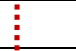 & & & & & & & & & \\
\hline C6 & & & & & & & & & & & & & & 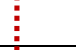 & & & & & & & & & \\
\hline C7 & & & & & & & & & & & & & & $!$ & & & & & & & $\rightarrow$ & & $\mathrm{m}$ \\
\hline $\mathrm{C} 8$ & & & & & & & & & & & & & & 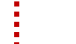 & & & & & & & & & \\
\hline C9 & & & & & & & & & & & & & & 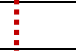 & & & & & & & & & \\
\hline $\mathrm{C} 10$ & & & & & & & & & & & & & & 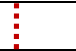 & & & & & & & & & \\
\hline $\mathrm{C} 11$ & & & & & & & & & & & & & & 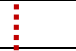 & & & & & & & & & \\
\hline $\mathrm{C} 12$ & & & & & & & & & & & & & & 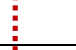 & & & & & & & & & \\
\hline $\mathrm{C} 13$ & & & & & & & & & & & & & & 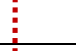 & & & & & & & & & \\
\hline $\mathrm{C} 14$ & 4 & 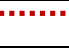 & & & & & & & :-.." & & & 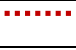 & & .1 & & & & & & & & & \\
\hline$\ldots$ & & & & & & & & & & & & & & & & & & & & & & & \\
\hline$\ldots .$. & & & & & & & & & & & & & & & & & & & & & & & \\
\hline$\ldots \ldots$ & & & & & & & & & & & & & & & & & & & & & & & \\
\hline C21 & & & & & & & & & & & & & & & 1 & & & & & & & & \\
\hline
\end{tabular}


Please consider the relative aspects and provide the criteria's influence level in all blanks.

For instance, what is the influence level (NI, VLI, LI, HI, VHI) between Sustainable business performance (A1) and the Sustainable economy of rural society (A2)? The assessment of aspect to aspect

\begin{tabular}{|c|c|c|c|c|c|}
\hline & A1 & A2 & A3 & A4 & A5portance level \\
\hline A1 & & & & & \\
\hline A2 & & & & & \\
\hline A3 & & & & & \\
\hline A4 & & & & & \\
\hline A5 & & & & \\
\hline
\end{tabular}

The assessment of criterion to criterion

\begin{tabular}{|c|c|c|c|c|c|c|c|c|c|c|c|c|c|c|c|c|c|c|c|c|c|c|}
\hline & C1 & $\mathrm{C} 2$ & C3 & C4 & C5 & C6 & C7 & C8 & C9 & $\mathrm{C} 10$ & C11 & C12 & $\mathrm{C} 13$ & C14 & C15 & C16 & C17 & $\mathrm{C} 18$ & C19 & $\mathrm{C} 20$ & $\mathrm{C} 21$ & Importance level \\
\hline $\mathrm{C} 1$ & & & & & & & & & & & & & & & & & & & & & & \\
\hline $\mathrm{C} 2$ & & & & & & & & & & & & & & & & & & & & & & \\
\hline C3 & & & & & & & & & & & & & & & & & & & & & & \\
\hline C4 & & & & & & & & & & & & & & & & & & & & & & \\
\hline C5 & & & & & & & & & & & & & & & & & & & & & & \\
\hline C6 & & & & & & & & & & & & & & & & & & & & & & \\
\hline C7 & & & & & & & & & & & & & & & & & & & & & & \\
\hline C8 & & & & & & & & & & & & & & & & & & & & & & \\
\hline C9 & & & & & & & & & & & & & & & & & & & & & & \\
\hline C10 & & & & & & & & & & & & & & & & & & & & & & \\
\hline C11 & & & & & & & & & & & & & & & & & & & & & & \\
\hline $\mathrm{C} 12$ & & & & & & & & & & & & & & & & & & & & & & \\
\hline $\mathrm{C} 13$ & & & & & & & & & & & & & & & & & & & & & & \\
\hline C14 & & & & & & & & & & & & & & & & & & & & & & \\
\hline C15 & & & & & & & & & & & & & & & & & & & & & & \\
\hline C16 & & & & & & & & & & & & & & & & & & & & & & \\
\hline C17 & & & & & & & & & & & & & & & & & & & & & & \\
\hline C18 & & & & & & & & & & & & & & & & & & & & & & \\
\hline C19 & & & & & & & & & & & & & & & & & & & & & & \\
\hline C20 & & & & & & & & & & & & & & & & & & & & & & \\
\hline C21 & & & & & & & & & & & & & & & & & & & & & & \\
\hline
\end{tabular}




\section{References}

1. Phillip, S.; Hunter, C.; Blackstock, K. A typology for defining agritourism. Tour. Manag. 2010, 31, 754-758. [CrossRef]

2. Stoddard, J.E.; Pollard, C.E.; Evans, M.R. The triple bottom line: A framework for sustainable tourism development. Int. J. Hosp. Tour. Adm. 2012, 13, 233-258. [CrossRef]

3. Tseng, M.L.; Wu, K.J.; Lee, C.H.; Lim, M.K.; Bui, T.D.; Chen, C.C. Assessing sustainable tourism in Vietnam: A hierarchical structure approach. J. Clean. Prod. 2018, 195, 406-417. [CrossRef]

4. Shih, D.H.; Lu, C.M.; Lee, C.H.; Cai, S.Y.; Wu, K.J.; Tseng, M.L. Eco-innovation in circular agri-business. Sustainability. 2018, 10, 1140. [CrossRef]

5. Shih, D.H.; Lu, C.M.; Lee, C.H.; Parng, Y.J.M.; Wu, K.J.; Tseng, M.L. A Strategic Knowledge Management Approach to Circular Agribusiness. Sustainability. 2018, 10, 2389. [CrossRef]

6. Wilson, J.; Thilmany, D.; Watson, P. The role of agritourism in Western states: Place-specific and policy factors influencing recreational income for producers. Rev. Reg. Stud. 2006, 36, 381-399.

7. Haggblade, S.; Hazell, P.; Reardon, T. The rural non-farm economy: Prospects for growth and poverty reduction. World Dev. 2010, 38, 1429-1441. [CrossRef]

8. Joo, H.; Khanal, A.R.; Mishra, A.K. Farmers' participation in agritourism: Does it affect the bottom line? Agric. Resour. Econ. Rev. 2013, 42, 471-490. [CrossRef]

9. Choo, H.; Petrick, J.F. Social interactions and intentions to revisit for agritourism service encounters. Tour. Manag. 2014, 40, 372-381. [CrossRef]

10. Busby, G.; Rendle, S. The transition from tourism on farms to farm tourism. Tour. Manag. 2000, 21, 635-642. [CrossRef]

11. McGehee, N.G.; Kim, K. Motivation for agri-tourism entrepreneurship. J. Travel Res. 2004, 43, 161-170. [CrossRef]

12. Yang, L. Impacts and challenges in agritourism development in Yunnan, China. Tour. Plan. Dev. 2012, 9, 369-381. [CrossRef]

13. Barbieri, C. Assessing the sustainability of agritourism in the US: A comparison between agritourism and other farm entrepreneurial ventures. J. Sustain. Tour. 2013, 21, 252-270. [CrossRef]

14. Kline, C.; Barbieri, C.; LaPan, C. The influence of agritourism on niche meats loyalty and purchasing. J. Travel Res. 2016, 55, 643-658. [CrossRef]

15. Kim, S.; Lee, S.K.; Lee, D.; Jeong, J.; Moon, J. The effect of Agri-tourism experience on consumers' future food purchase patterns. Tour. Manag. 2019, 70, 144-152. [CrossRef]

16. Wu, K.J.; Zhu, Y.; Cheng, Q.; Tseng, M.L. Coordinated triple bottom line approach to sustainable tourism under uncertainty: Proposed a Hierarchical Framework. J. Clean. Prod 2019, in press. [CrossRef]

17. Chen, R.H.; Lin, Y.H.; Tseng, M.L. Multi-criteria analysis of sustainable development indicators in the construction minerals industry in China. Resour Policy 2014, 46, 123-133. [CrossRef]

18. Sonnino, R. For a 'piece of bread'? Interpreting sustainable development through agritourism in Southern Tuscany. Sociol. Rural. 2004, 44, 285-300. [CrossRef]

19. Tseng, M.L.; Lin, R.J.; Chen, H.P. Evaluating the effectiveness of e-learning system in uncertainty. Ind. Manag. Data Syst. 2010, 111, 869-889. [CrossRef]

20. Barbieri, C.; Xu, S.; Gil-Arroyo, C.; Rich, S.R. Agritourism, farm visit, or a branding assessment for recreation on farms. J. Travel Res. 2016, 55, 1094-1108. [CrossRef]

21. Sharpley, R.; Jepson, D. Rural tourism: A spiritual experience? Ann. Tour. Res. 2011, 38, 52-71. [CrossRef]

22. Lupi, C.; Giaccio, V.; Mastronardi, L.; Giannelli, A.; Scardera, A. Exploring the features of agritourism and its contribution to rural development in Italy. Land Use Policy. 2017, 64, 383-390. [CrossRef]

23. Barbieri, C.; Mshenga, P.M. The role of the firm and owner characteristics on the performance of agritourism farms. Sociol. Rural. 2008, 48, 166-183. [CrossRef]

24. Bowler, I.; Clark, G.; Crockett, A.; Ilbery, B.; Shaw, A. The development of alternative farm enterprises: A study of family labour farms in the Northern Pennines of England. J. Rural Stud. 1996, 12, 285-295. [CrossRef]

25. Albu, R.G.; Nicolau, L.C. Sustainable Development of the Romanian Rural Areas within the Present European Context. Bulletin of the Transilvania University of Brasov. Econ. Sci. Ser. V 2011, 4, 111. 
26. Garau, C. Perspectives on cultural and sustainable rural tourism in a smart region: The case study of Marmilla in Sardinia (Italy). Sustainability. 2015, 7, 6412-6434. [CrossRef]

27. Brandth, B.; Haugen, M.S. Gendered work in family farm tourism. J. Comp. Fam. Stud. 2007, 38, $379-393$. [CrossRef]

28. Koutsouris, A.; Gidarakou, I.; Grava, F.; Michailidis, A. The phantom of (agri) tourism and agriculture symbiosis? A Greek case study. Tour. Manag. Perspect. 2014, 12, 94-103. [CrossRef]

29. DeRosa, M.; McElwee, G.; Smith, R. Farm diversification strategies in response to rural policy: A case from rural Italy. Land Use Policy 2019, 81, 291-301. [CrossRef]

30. McGehee, N.G. An agritourism systems model: A Weberian perspective. J. Sustain. Tour. 2007, 15, 111-124. [CrossRef]

31. Ollenburg, C.; Buckley, R. Stated economic and social motivations of farm tourism operators. J. Travel Res. 2007, 45, 444-452. [CrossRef]

32. Lee, C.H.; Wu, K.J.; Tseng, M.L. Resource management practice through eco-innovation toward sustainable development using qualitative information and quantitative data. J. Clean. Prod. 2018, 202, 120-129. [CrossRef]

33. Viglia, G.; Abrate, G. When distinction does not pay off-Investigating the determinants of European agritourism prices. J. Bus. Res. 2017, 80, 45-52. [CrossRef]

34. Barbieri, C.; Mahoney, E.; Butler, L. Understanding the nature and extent of farm and ranch diversification in North America. Rural Sociol. 2008, 73, 205-229. [CrossRef]

35. Boley, B.B.; Perdue, R.R. Destination management, competitiveness, and quality-of-life: A review of literature and research agenda. In Handbook of Tourism and Quality-of-Life Research; Springer: Dordrecht, The Netherlands, 2012; pp. 515-528.

36. McGehee, N.G.; Boley, B.B.; Hallo, J.C.; McGee, J.A.; Norman, W.; Oh, C.O.; Goetcheus, C. Doing sustainability: An application of an inter-disciplinary and mixed-method approach to a regional sustainable tourism project. J. Sustain. Tour. 2013, 21, 355-375. [CrossRef]

37. Naidoo, P.; Sharpley, R. Local perceptions of the relative contributions of enclave tourism and agritourism to community well-being: The case of Mauritius. J. Destin. Mark. Manag. 2016, 5, 16-25. [CrossRef]

38. Wu, W.W.; Lee, Y.T.; Tseng, M.L.; Chiang, Y.H. Data mining for exploring hidden patterns between KM and its performance. Knowl. Based Syst. 2010, 23, 397-401. [CrossRef]

39. Roberts, S.; Tribe, J. Sustainability indicators for small tourism enterprises-An exploratory perspective. J. Sustain. Tour. 2008, 16, 575-594. [CrossRef]

40. Tyrrell, T.; Paris, C.M.; Biaett, V. A quantified triple bottom line for tourism: Experimental results. J. Travel Res. 2013, 52, 279-293. [CrossRef]

41. McNally, S. Farm diversification in England and Wales-What can we learn from the farm business survey? J. Rural Stud. 2001, 17, 247-257. [CrossRef]

42. McElwee, G. Farmers as entrepreneurs: Developing competitive skills. J. Dev. Entrep. 2006, 11, $187-206$. [CrossRef]

43. Wang, S.; Sun, X.; Song, M. Environmental regulation, resource misallocation and ecological efficiency. Emerg. Mark. Trade 2019, in press. [CrossRef]

44. Turner, M.M.; Whitehead, I.; Millard, N. The Effects of Public Funding on Farmers' Attitudes to Farm Diversification; University of Exeter: Exeter, UK, 2006.

45. Barbieri, C.; Mahoney, E. Why is diversification an attractive farm adjustment strategy? Insights from Texas farmers and ranchers. J. Rural Stud. 2009, 25, 58-66. [CrossRef]

46. Turner, M.M.; Winter, M.; Barr, D.A.; Fogerty, M.W.; Errington, A.; Lobley, M.; Reed, M.J. Farm diversification activities 2002: Benchmarking study. In Final Report by the Universities of Exeter and Plymouth to Defra; University of Exeter: Exeter, UK, 2003.

47. Pratt, S.; Suntikul, W.; Dorji, U. Economic sustainability? Examining the linkages and leakages between agriculture and hotels in B hutan. Int. J. Tour. Res. 2018, 20, 626-636. [CrossRef]

48. Tew, C.; Barbieri, C. The perceived benefits of agritourism: The provider's perspective. Tour. Manag. 2012, 33, 215-224. [CrossRef]

49. Choi, H.C.; Sirakaya, E. Sustainability indicators for managing community tourism. Tour. Manag. 2006, 27, 1274-1289. [CrossRef] 
50. Tanguay, G.A.; Rajaonson, J.; Therrien, M.C. Sustainable tourism indicators: Selection criteria for policy implementation and scientific recognition. J. Sustain. Tour. 2013, 21, 862-879. [CrossRef]

51. Cui, L.; Song, M. Economic evaluation of the Belt and Road Initiative from an unimpeded trade perspective. Int. J. Logist. Res. Appl. 2019, 22, 25-46. [CrossRef]

52. Lewis, J.B.; Delisle, L. Tourism as economic self-development in rural Nebraska: A case study. Tour. Anal. 2004, 9, 153-166. [CrossRef]

53. Opricovic, S.; Tzeng, G.H. Compromise solution by MCDM methods: A comparative analysis of VIKOR and TOPSIS. Eur. J. Oper. Res. 2004, 156, 445-455. [CrossRef]

54. Kaufmann, A.; Gupta, M.M. Introduction to Fuzzy Arithmetic; Van Nostrand Reinhold: New York, NY, USA, 1991.

55. Gabus, A.; Fontela, E. World Problems, an Invitation to Further Thought Within the Framework of Dematel; Battelle Geneva Research Center: Geneva, Switzerland, 1972; pp. 1-8.

(C) 2019 by the authors. Licensee MDPI, Basel, Switzerland. This article is an open access article distributed under the terms and conditions of the Creative Commons Attribution (CC BY) license (http://creativecommons.org/licenses/by/4.0/). 